\title{
AWARENESS OF OBSTETRIC DANGER SIGNS AND ASSOCIATED FACTORS AMONG PREGNANT WOMEN WHO ATTEND ANTENATAL CARE IN PUBLIC HEALTH INSTITUTIONS OF ADAMA CITY, OROMIA, ETHIOPIA
}

\author{
Natnaael kidanu Yibalih ${ }^{1}$, Worku Dugassa ${ }^{2}$, Addis Alemu ${ }^{3}$ \\ ${ }^{1}$ School of Medicine, Aksum University, College of health science and comprehensive \\ specialized hospital, Aksum, Ethiopia, \\ ORCID:0000-0002-1141-8360 \\ ${ }^{2}$ Department of public health, Adama Hospital Medical College, Adama, Ethiopia \\ ${ }^{3}$ Department of Ophthalmology, Adama Hospital Medical College, Adama, Ethiopia
}

\begin{abstract}
*Corresponding Author: Natnaael kidanu Yibalih
Corresponding Author Email: natnaelk1976@gmail.com

Article Received: 30-09-19 Accepted: 29-10-19

Published: 05-11-19

Licensing Details: Author retains the right of this article. The article is distributed under the terms of the $\begin{array}{lllll}\text { Creative } & \text { Commons } & \text { Attribution-NonCommercial } & 4.0 & \text { License }\end{array}$ (http://www.creativecommons.org/licences/by-nc/4.0/) which permits non-commercial use, reproduction and distribution of the work without further permission provided the original work is attributed as specified on the Journal open access page
\end{abstract}

\begin{abstract}
Improving awareness of women about obstetric danger signs of pregnancy, labor, and postpartum period is the crucial first step in accepting appropriate and timely health care service. In Ethiopia, where pregnancy related complications and maternal death is high, little is known about level of awareness of obstetric danger signs. The aim of this study was to assess Awareness of Obstetric Danger Signs and Associated Factors among Pregnant Women who attend Ante-natal care in Public Health Institutions of Adama City, Oromia, Ethiopia, 2018.

Institutional based cross-sectional study was conducted from October 2017 to April 2018 and a total of 381 pregnant women were selected using Systematic random sampling technique. Interviewer administered structured Questionnaire was used to collect data. Data were cleaned and analyzed using EPI-INFO version 7 and SPSS window version 20. Bivariate and multi
\end{abstract}


variable Logistic regression was used to assess association between awareness of obstetric danger signs and various independent variables.

A total of 381 pregnant women were participated with $100 \%$ response rate. Of all participants about $44.4 \%$ knew seven and above obstetric danger signs of pregnancy, labor, and postpartum period. Out of the 381 participants 261 (68.5\%), 240 (63\%) and 164 (43\%) knew at least two danger signs during pregnancy, childbirth and postpartum period, respectively. Vaginal bleeding was the most commonly mentioned danger signs of pregnancy $(59.8 \%)$, labor $(66.1 \%)$ and postpartum (60.4\%). In multivariate logistic regression analysis, maternal and husband educational status, residence, and sources of obstetric danger signs related information were significantly associated with awareness of obstetric danger signs.

Awareness of women about obstetric danger signs of pregnancy, labor, and postpartum period was low and affected by Partner \& maternal educational status, sources of obstetric danger signs related information, and residence. Therefore, it needs to raise women's awareness of danger signs and associated factors through maternal and child health service by designing appropriate strategies including provision of targeted information, education, and communication.

Keywords: Pregnant Women, Antenatal Care Follow Up, Awareness, Obstetric Danger Signs, Ethiopia

\section{Background}

\section{INTRODUCTION}

Pregnancy, also known as gestation, is a very important event from both social and medical points of view. Therefore, pregnant women should receive special concern and attention from the family, society, and health care system. The major aim of focused antenatal care which was adopted by the World Health Organization (WHO) in 2002 is to improve quality of antenatal care (ANC) and increase its coverage by: identification of pre-existing health conditions, health promotion and disease prevention, early detection and treatment of complications arising during pregnancy, and planning for birth preparedness and complication readiness [1-4].

Danger signs are symptoms and signs that are recognized by non-health professional persons without difficulty. They are categorized in to pregnancy, childbirth, and postpartum periods. The main danger signs during pregnancy include vaginal bleeding, labor before due date, excessive vomiting, decreased or no fetal movement, feeling very weak or tired, and blurred vision. Main danger signs during childbirth include severe vaginal bleeding, malposition of the fetus, prolonged labor, convulsions, and retained placenta. Main danger signs during postpartum include severe vaginal bleeding, loss of consciousness, convulsion, painful swelling of one leg, and high grade fever [3, 5-7].

Women should be empowered with good awareness of obstetric danger signs (ODS) of pregnancy, delivery and postpartum because every pregnancy can be faced with risks. Therefore, good awareness will help women and their families to make on time decisions, seek obstetric care, and prepare themselves before birth for possible complications. Birth preparedness and complication readiness enables women to identify a skilled care provider and appropriate health 
facility, saving money, identifying compatible blood donors, and arranging transportation plans (3, 6-10). However, in developing countries like Ethiopia birth preparedness and complication readiness is low due to low awareness of ODS. A study done in Rwanda showed that out of 350 women, $84.6 \%, 77.4 \%$, and $82.3 \%$ mentioned at least one key danger sign during pregnancy, labor, and postpartum respectively, but only $6.6 \%$ mentioned three or more key danger signs during all three periods and with regard to birth preparedness, 22.3\% were well prepared [11]. According to study done in Haiti, Malawi, and Senegal clients' overall knowledge of danger signs was low [12]. Ethiopia in Goba woreda, 82(14.6\%) of respondents were knowledgeable about birth preparedness and complication readiness (13).

Worldwide, the maternal mortality ratio (MMR) dropped by about 44\% between 1990 and 2015 . However, in developing countries MMR is a substantial burden with overall MMR of 239 (UI 229 to 275) which is roughly 20 times higher than that of developed regions, where it is just 12 (UI 11 to 14). Developing regions account for approximately 99\% (302,000) of the global maternal deaths in 2015, with sub-Saharan Africa alone accounting for roughly $66 \%(201,000)$, followed by Southern Asia (66,000) [6].

In Ethiopia, maternal morbidity and mortality are among the highest in the world [7, 8]. Ethiopian demographic and health survey (EDHS) 2016 showed MMR of 412 deaths per 100,000 live births which is lower than EDHS 2011 report of 676 (8). But still it is high because the national reproductive health strategy (NRHS) of Ethiopia was targeted to reduce the high maternal and neonatal mortality to 350 deaths per 100,000 and 18 deaths per 1,000 live births by the year 2015, respectively [9]. Thus, to achieve the target of decreasing MMR to 199 per 100,000 live births under the Sustainable Development Goals (SDGs) by 2019/20, increased awareness of obstetric danger signs is needed [14].

According to NRHS of Ethiopia, it was proposed that $80 \%$ of all households/families should recognize at least three danger signs of obstetric complications by 2010 [9]. However, EDHS 2016 report showed that among the women who had a live birth in the 5 years before the survey, only $45 \%$ of women were informed of danger signs of pregnancy during ANC visits [8]. Low awareness of ODS together with low preparedness leads to high maternal morbidity and mortality. Maternal morbidly and mortality can be reduced to the needed level if women and their families empowered with good awareness of ODS that help them to decide on time and seek appropriate health care [4, 15-18].

In Ethiopia, the NRHS has given emphasis to improve awareness of women on obstetric danger signs since 2006 (9). However, study findings in different parts of Ethiopia showed that awareness of ODS is poor and little is known about its associated factors [19-23]. Studies done at debrabirhan town revealed that $137(38.6 \%)$ of the respondents were knowledgeable about danger signs during pregnancy [19]. Other research findings from Mekelle city, Tsegedie, and Debark town showed that mother's awareness on danger signs of pregnancy was poor and affected by age, possession of TV/radio, educational status, and occupation [20-22].

Therefore, the aim of this study was to assess the current status of awareness of obstetric danger signs and associated factors among pregnant women in Public Health Institutions of Adama City, 
Oromia, Ethiopia. The study findings can be used as a base line for the study area since no such study was done in the city. It is also necessary for planners, health service providers, management teams, and stakeholders for modifying and improving awareness of ODS and the quality of ANC services thereby for early prevention of maternal morbidity and mortality.

\section{Study Area and Period}

\section{MATERIALS AND METHODS}

This study was conducted from October 2017 to April 2018 in Adama City, the previous capital city of Oromia Region. It is located 100 kilometers southeast of Addis Ababa, the capital city of Ethiopia. According to 2008 E.C Adama city municipality report, this city has a total population of 337,516, of whom 170, 445 were women and 167, 070 men. There are 8 public health institutions. Of which one hospital that serves as referral and teaching center and the rest are health centers. All of the health institutions provide maternal and child health care service. There are also five private hospitals and 38 private clinics in the city. According to the information from the administration office of Adama hospital medical college (AHMC) its coverage area includes Adama City, majority of East Shoa districts, West Harerge, some parts of Arsi zone, some woredas from Amhara, Afar, and sometimes from Somali regional states.

\section{Study Design and Population}

An Institutional based cross-sectional study was conducted. Source of Population for the study were all pregnant women who attend ANC service in public health institutions of Adama City. Study Population were randomly selected pregnant women who attend ANC service in the randomly selected public health institutions. Critically ill mothers, unable to hear/ communicate, women with mental health problem, and pregnant women who came for the second time during data collection period were excluded from the study.

\section{Sample Size and Sampling Procedure}

The sample size was calculated using single population proportion formula, by considering the following assumptions. The proportion ( $\mathrm{p}$ ) of knowledge on danger sign of pregnancy from the previous study $=82.5 \%(20), 95 \%$ confidence level of $(\mathrm{Z} \alpha / 2)^{2}=1.96,4 \%$ of absolute precision, and $10 \%$ non-response rate. Hence, the total sample size was 381 .

Systematic random sampling technique was employed to include study participants who meet the inclusion criteria after proportional sample size was allocated to the selected health institutions. The average number of new pregnant women coming to each selected health institutions was identified by conducting a preliminary survey. The proportional sample size was allocated to the four health institutions (one hospital and three health centers) accordingly. Finally, the study participants were selected by calculating ' $\mathrm{k}$ ' value (by dividing number of pregnant women coming to the health institution to sample size). Then every $\mathrm{k}^{\text {th }}$ individuals was selected to participate in the study and the first pregnant woman included in the study was selected by lottery method. 


\section{Data Collection Procedure and Management}

Pre-tested structured questionnaire was used to obtain information on socio-demographic, obstetric history, and awareness of women about danger signs of pregnancy, childbirth, and postpartum. Questionnaire for this study was adopted from 'Safe Motherhood questionnaire' as developed by Jhpiego's Maternal and Neonatal Health Program and other similar studies [3, 20, 21]. For its understanding, the questionnaire was translated to the local language (Amharic and Afan Oromo) by two different individuals and then translated back to English for its consistency during data entry. Data were collected using interviewer administered structured questionnaire by 4 BSc. midwives after they have taken one day training about data collection by the principal investigator. Questionnaires were pre-tested on $10 \%$ of samples before the actual data collection and correction was incorporated in the final questionnaires. Regular and continues supervision was made by the principal investigator to monitor quality of the data collection process and feed backs were given to data collectors.

\section{Study Variables}

Dependent variable was Awareness of Obstetric Danger Signs and the Independent variables were Socio-demographic variables (Age, Level of education, marital status, religion, residence, ethnic group, occupation, monthly income, partner level of education, and partner occupation) and Obstetric Variables (Gravidity, parity, number of ANC visits).

\section{Operational Definitions}

Awareness on main danger signs of pregnancy: A woman was considered as had good awareness on main danger signs of pregnancy, if she can mention at least two of the main danger signs for pregnancy spontaneously.

Awareness on main danger signs of labor /child birth: A woman was considered as had good awareness on main danger signs of labor/childbirth, if she can mention at least three of the main danger signs for labor/childbirth spontaneously.

Awareness on main danger signs of puerperium/postpartum: A woman was considered as had good awareness on main danger signs of Puerperium, if she can mention at least two of the main danger signs for puerperium spontaneously.

Awareness of Obstetric Danger Signs: A woman was considered as had good awareness on Obstetric Danger Signs, if she can mention at least seven main danger signs during any of the three periods (pregnancy, labor, and postpartum).

Danger signs: Are not the actual obstetric complications, but symptoms and signs that are easily recognized by non-health professional persons.

\section{Data Processing, Presentation and Analysis}

Data were coded, entered and cleaned using EPI-INFO version 7 and further cleaned and analyzed using SPSS window version 20. Descriptive and summary statistics were done. Both bivariate and multivariate logistic regression was used to see the association between each independent variable with awareness of danger signs. Odds ratio with their $95 \%$ confidence 
intervals were computed to identify the presence and strength of association, and statistical significance was declared if $\mathrm{p}<0.05$.

\section{Ethical Consideration}

Ethical clearance was obtained from institutional Review Board (IRB) of Adama Hospital Medical College, school of medicine. Official letter was sent to Oromia Regional health bureau and Adama city local health office. Then a letter from Adama city local health office was submitted to the selected health institutions to get permission. Respondents were informed about the purpose of the study and informed consent was received from each participant. Participants were also informed that they have full right to discontinue or refuse to participate in the study. To ensure confidentiality, the name of interviewee was not written on the questionnaire. Besides, each respondent was assured that the information provided by them was confidential and used only for the purpose of research.

\section{Socio-Demographic Characteristics}

\section{RESULT}

A total of 381 pregnant women were participated in the study and the response rate was $100 \%$. The mean age of the respondents was $27 \pm 5.8$ year (Table 1). Educational status of respondents and their husbands was illustrated in Fig 1. Educational status distribution of women who attend ANC in public health institutions of Adama city, Ethiopia and their husbands in 2018 G.C.

Table 1: Socio-demographic characteristics of women who attend ANC in public health institutions of Adama city, Oromia, Ethiopia 2018.

\begin{tabular}{|l|l|l|l|}
\hline Variables & Categories & Frequency & Percent \\
\hline Age in years & $18-24$ & 135 & 35.4 \\
\cline { 2 - 4 } & $25-30$ & 161 & 42.3 \\
\cline { 2 - 4 } & $31+$ & 85 & 22.3 \\
\hline \multirow{5}{*}{ Ethnicity } & Oromo & 178 & 46.7 \\
\cline { 2 - 4 } & Amhara & 96 & 25.2 \\
\cline { 2 - 4 } & Gurage & 60 & 15.8 \\
\cline { 2 - 4 } & Others* & 47 & 12.3 \\
\hline \multirow{5}{*}{ Religion } & Orthodox & 225 & 59.1 \\
\cline { 2 - 4 } & Muslim & 119 & 31.2 \\
\cline { 2 - 4 } & Protestant & 37 & 9.7 \\
\hline Marital status & Single & 30 & 7.9 \\
\cline { 2 - 4 } & Married & 331 & 86.9 \\
\cline { 2 - 4 } & Divorced & 20 & 5.2 \\
\hline Residence & Urban & 323 & 84.8 \\
\cline { 2 - 4 } & Rural & 58 & 15.2 \\
\hline Monthly income & $100-500$ & 40 & 10.5 \\
\cline { 2 - 4 } & $501-1000$ & 76 & 19.9 \\
\cline { 2 - 4 } & $1001-2000$ & 96 & 25.2 \\
\cline { 2 - 4 } & $\geq 2001$ & 169 & 44.4 \\
\hline \multirow{5}{*}{ Occupation } & Trader & 21 & 5.5 \\
\cline { 2 - 4 } & Housewife & 77 & 56.4 \\
\cline { 2 - 4 } & Government employee & 20.2 \\
\cline { 2 - 4 } & Private & & 17.9 \\
\hline
\end{tabular}




\begin{tabular}{|l|l|c|c|}
\hline \multirow{2}{*}{$\begin{array}{l}\text { Sources of information for obstetric danger } \\
\text { signs }\end{array}$} & $\begin{array}{l}\text { TV/Radio/Reading related } \\
\text { books/internet }\end{array}$ & 251 & 65.9 \\
\cline { 2 - 4 } & No sources of information & 130 & 34.1 \\
\hline Traveling time to HI & $<1$ hour & 315 & 82.7 \\
\cline { 2 - 4 } & $\geq 1$ hour & 66 & 17.3 \\
\hline
\end{tabular}

Others* $=$ Tigray, Silite, Sidama

\section{Obstetric Characteristics of Respondents}

Regarding their number of pregnancy 176(46.2\%) were primigravida and 205(53.8\%) had 2 and above number of pregnancies. Regarding their parity 176 (46.2\%) were nullipara, 108 (28.3\%) were primipara, and 97 (25.5\%) were multipara. Of the participants $112(29.4 \%)$ had one ANC visit, 137 (36\%) has two ANC visits, and 132 (34.6\%) had three and above ANC visits. Regarding gestational age in months while ANC follow up started 148 (38.8\%) of participants started during their first trimester and 233 (61.2\%) were started during their second and third trimester.

\section{Awareness of Study Participants on Obstetric Danger Signs}

Of the participants 169 (44.4\%) knew seven and above obstetric danger signs (ODS) during any of the three periods (pregnancy, labor, and postpartum). Of the participants, $354(92.4 \%)$ knew at least one danger sign, $317(83.2 \%)$ knew at least two danger signs, and $290(76.1 \%)$ knew at least three danger signs during any of the three periods. During pregnancy $337(88.5 \%)$ and 261(68.5\%) participants knew at least one and 2 danger signs respectively. During labor 314 (82.4\%) and 240(63\%) participants knew at least one and 2 danger signs respectively. During postpartum $272(71.4 \%)$ and $164(43 \%)$ participants knew at least one and 2 danger signs respectively.

Of the respondents 269(70.6\%) knew severe nausea and excessive vomiting during pregnancy, $39(10.2 \%)$ knew pain or swelling or pus discharge from episiotomy or cesarean section site during postpartum. Of the respondents 221 (58\%) knew retained placenta, 115 (30.2\%) knew prolonged labor, and $66(17.3 \%)$ knew malposition during labor. Of the total participants 71 (18.6\%) knew labor before due date and 147 (38.6\%) knew gush of fluid per vagina during pregnancy. Regarding foul smelling vaginal discharge 22 (5.8\%) and 73 (19.2\%) of participants had awareness during labor and postpartum respectively. Regarding painful swelling of one leg $20(5.2 \%)$ of participants had awareness during postpartum (Table 2).

Table 2: Awareness of study participants on obstetric danger sings in public health institutions of Adama city, Oromia, Ethiopia 2018.

\begin{tabular}{|l|l|l|l|l|l|l|l|}
\hline \multirow{2}{*}{ Obstetric danger signs } & \multicolumn{2}{l|}{ During Pregnancy } & \multicolumn{2}{l|}{ During child birth } & \multicolumn{2}{l|}{ During Postpartum } \\
\cline { 2 - 9 } & \multicolumn{2}{|l|}{ Number } & \%age & Number & $\%$ age & Number & $\%$ age \\
\hline Vaginal bleeding & Yes & 228 & 59.8 & 252 & 66.1 & 230 & 60.4 \\
\cline { 2 - 9 } & No & 153 & 40.2 & 129 & 33.9 & 151 & 39.6 \\
\hline Convulsion & Yes & 38 & 10 & 46 & 12.1 & 36 & 9.4 \\
\hline
\end{tabular}




\begin{tabular}{|c|c|c|c|c|c|c|c|}
\hline & No & 343 & 90 & 335 & 87.9 & 345 & 90.6 \\
\hline \multirow{2}{*}{ Loss of consciousness } & Yes & 33 & 8.7 & 37 & 9.7 & 24 & 6.3 \\
\hline & No & 348 & 91.3 & 344 & 90.3 & 357 & 93.7 \\
\hline \multirow[t]{2}{*}{ Severe abdominal pain } & Yes & 123 & 32.3 & 106 & 27.8 & 90 & 23.6 \\
\hline & No & 258 & 67.7 & 275 & 72.2 & 291 & 76.4 \\
\hline \multirow[t]{2}{*}{ Swelling of hands/face } & Yes & 125 & 32.8 & 68 & 17.8 & 65 & 17.1 \\
\hline & No & 256 & 67.2 & 313 & 82.2 & 316 & 82.9 \\
\hline \multirow{2}{*}{ Severe headache } & Yes & 150 & 39.4 & 79 & 20.7 & 64 & 16.8 \\
\hline & No & 231 & 60.6 & 302 & 79.3 & 317 & 83.2 \\
\hline \multirow{2}{*}{ Decreased or no fetal movement } & Yes & 158 & 41.5 & 130 & 34.1 & & \\
\hline & No & 223 & 58.5 & 251 & 65.9 & & \\
\hline \multirow[t]{2}{*}{ High grade fever } & Yes & 23 & 6 & 29 & 7.6 & 82 & 21.5 \\
\hline & No & 358 & 94 & 352 & 92.4 & 299 & 78.5 \\
\hline \multirow[t]{2}{*}{ Feeling very weak or tired (Anaemia) } & Yes & 170 & 44.6 & 88 & 23.1 & 119 & 31.2 \\
\hline & No & 211 & 55.4 & 293 & 76.9 & 262 & 68.8 \\
\hline \multirow[t]{2}{*}{ Chest pain and Shortness of breathing } & Yes & 59 & 15.5 & 72 & 18.9 & 30 & 7.9 \\
\hline & No & 322 & 84.5 & 309 & 81.1 & 351 & 92.1 \\
\hline \multirow[t]{2}{*}{ High blood pressure } & Yes & 44 & 11.5 & 46 & 12.1 & 36 & 9.4 \\
\hline & No & 337 & 88.5 & 335 & 87.9 & 345 & 90.6 \\
\hline \multirow[t]{2}{*}{ Blurred vision } & Yes & 102 & 26.8 & 82 & 21.5 & 61 & 16 \\
\hline & No & 279 & 73.2 & 299 & 78.5 & 320 & 84 \\
\hline
\end{tabular}

Factors associated with awareness of obstetric danger signs

\section{Bivariate Analysis}

The association between Awareness of obstetric danger signs and various independent variables was determined through bivariate analysis and those variables with $\mathrm{P}$-value of $<0.05$ were considered as a candidate for multivariate logistic regression model. The p-value was determined for each categorized variable. Awareness of obstetric danger signs were categorized into two in which the first group comprised of women that were mentioned less than seven and the second group comprised of women mentioned at least seven obstetric danger signs during any of the three periods (pregnancy, labor, and postpartum) so as to allow model development during regression development.

In the bivariate logistic regression analysis gestational age in months while ANC follow up started, average monthly income, travelling time to health institution, marital status, maternal and their husband occupation were not associated with awareness of obstetric danger signs. Age of mother, educational status of women and their husbands, number of current ANC follow up, sources of information about obstetric danger signs, number of pregnancies, and residence were significantly associated with awareness of obstetric danger signs at p-value $<0.05$ and taken to multivariate logistic regression model (Table 3).

\section{Multivariate Analysis}

In multivariate logistic regression analysis, educational status of mothers, residence, sources of information about obstetric danger signs, and partner educational level were significantly associated with awareness of obstetric danger signs (table 3). 
Table 3: Association between Awareness of obstetric danger signs and socio- demographic and obstetric variables among study participants in public health institutions of Adama city, Oromia, Ethiopia 2018.

\begin{tabular}{|c|c|c|c|c|c|}
\hline \multirow[t]{2}{*}{ Variables } & \multirow[t]{2}{*}{ Categories } & \multicolumn{2}{|c|}{ Awareness of ODS } & \multirow[t]{2}{*}{ COR ((95\%) } & \multirow[t]{2}{*}{ AOR (95\%) } \\
\hline & & Good & Low & & \\
\hline \multirow[t]{3}{*}{ Age in years } & $18-24$ & $18(13.3 \%)$ & $117(86.7 \%)$ & 1 & 1 \\
\hline & $25-30$ & $83(51.6 \%)$ & $78(48.4 \%)$ & $6.92(3.86-12.41)$ & $0.51(0.19-1.36)$ \\
\hline & $31+$ & $68(80 \%)$ & $17(20 \%)$ & $26(12.57-53.80)$ & $1.41(0.46-4.31)$ \\
\hline \multirow[t]{2}{*}{ № of pregnancy } & Primigravida & $34(19.3 \%)$ & $142(80.7 \%)$ & 1 & 1 \\
\hline & Multigravida & $135(65.9 \%)$ & $70(34.1 \%)$ & $8.06(5.02-12.92)$ & $1.76(0.90-3.48)$ \\
\hline \multirow{4}{*}{$\begin{array}{l}\text { Maternal } \\
\text { educational } \\
\text { status }\end{array}$} & Illiterate & $6(6.6 \%)$ & $85(93.4 \%)$ & 1 & 1 \\
\hline & Elementary & $11(12 \%)$ & $81(88 \%)$ & $1.92(0.68-5.44)$ & $0.65(0.18-2.31)$ \\
\hline & High school & $73(69.5 \%)$ & $32(30.5 \%)$ & $32.32(12.80-81.61)$ & $4.21(1.10-16.15)^{*}$ \\
\hline & Diploma \& above & $79(84.9 \%)$ & $14(15.1 \%)$ & $79.94(29.29-218.22)$ & $10.20(2.45-42.41) *$ \\
\hline \multirow{4}{*}{$\begin{array}{l}\text { Husband } \\
\text { educational } \\
\text { status }\end{array}$} & Illiterate & $6(6.8 \%)$ & $82(93.2 \%)$ & 1 & 1 \\
\hline & Elementary & $8(10.1 \%)$ & 71 (89.9) & $1.54(0.51-4.65)$ & $1.44(0.43-4.87)$ \\
\hline & High school & $58(66.7 \%)$ & $29(33.3 \%)$ & $27.33(10.67-70.05)$ & $5.50(1.58-19.10)^{*}$ \\
\hline & Diploma \& above & $97(76.4 \%)$ & $30(23.6 \%)$ & $44.19(17.53-111.39)$ & $4.17(1.17-14.85)^{*}$ \\
\hline \multirow[t]{2}{*}{ Residence } & Rural & $6(10.3 \%)$ & $52(89.7 \%)$ & 1 & 1 \\
\hline & Urban & $163(50.5 \%)$ & $160(49.5 \%)$ & $8.83(3.69-21.13)$ & $5.69(2.14-15.08)^{*}$ \\
\hline \multirow{3}{*}{$\begin{array}{l}\text { № of current } \\
\text { ANC follow up }\end{array}$} & 1 visit & $23(20.5 \%)$ & $89(79.5 \%)$ & 1 & 1 \\
\hline & 2 visit & $55(40.1 \%)$ & $82(59.9 \%)$ & $2.60(1.47-4.60)$ & $1.43(0.59-3.48)$ \\
\hline & $\geq 3$ visit & $91(68.9 \%)$ & $41(31.1 \%)$ & $8.59(4.77-15.47)$ & $1.56(0.63-3.87)$ \\
\hline \multirow{2}{*}{$\begin{array}{ll}\text { Sources } & \text { of } \\
\text { information } & \\
\text { about ODS } & \end{array}$} & No & $8(6.2 \%)$ & $122(93.8 \%)$ & 1 & 1 \\
\hline & $\begin{array}{l}\text { TV/Radio/ODS } \\
\text { related reading }\end{array}$ & $161(64.1 \%)$ & $90(35.9 \%)$ & $27.28(12.75-58.36)$ & $3.03(1.05-8.75)^{*}$ \\
\hline
\end{tabular}

The numbers with asterisk $(*)$ showed that statistically significant association between dependent and independent variables at $\mathrm{p}$-value $<0.05$

\section{Discussion}

The aim of the study was to assess awareness of pregnant women on obstetric danger signs and associated factors in public health institutions of Adama city. The study showed that the level of awareness of obstetric danger signs of pregnancy, labor, and postpartum period among pregnant women was $44.4 \%$. This was higher than a study done in Tanzania that showed only $25.2 \%$ of respondents were knowledgeable about obstetric danger signs during pregnancy, labor and postpartum [23]. This might be due to resident and sociocultural difference of study population and difference in national health policy implementation strategy of the two countries. Another possible explanation might be the Ethiopian government is doing well on maternal and child health through urban and rural health extension workers that works through home to home visiting and introducing important information about danger signs of obstetric complications.

Our study showed that $68.5 \%$ of women knew at least two danger signs during pregnancy, $63 \%$ during labor, and $43 \%$ during postpartum. This finding was higher than a study done in Tsegedie 
that showed $58.8 \%$ and $61.6 \%$ of respondents mentioned at least two danger signs of pregnancy and childbirth respectively [21] and in Aleta Wondo that showed out of 743 pregnant women $30.4 \%, 41.3 \%$, and $37.7 \%$ knew at least two danger signs during pregnancy, childbirth, and postpartum period, respectively [27]. This difference might be due to the fact that these two areas are located at the periphery of Ethiopia so women live at this remote area have restricted availability of health care service and information communication, educational accessibility compared to those women who live at Adama city. In addition, health providers may give low emphasis to danger signs during ANC follow up.

This study revealed that vaginal bleeding was the most common sign spontaneously mentioned by participants as danger signs of pregnancy (59.8\%), labor $(66.1 \%)$, and postpartum $(60.4 \%)$. This was nearly similar to study done in Northwest Ethiopia showed that vaginal bleeding was the most frequently recalled danger sign of obstetric complications by $60.2 \%, 56.8 \%$, and $53.8 \%$ respondents during pregnancy, labor, and postpartum periods, respectively [30]. This similarity might be due to similar implementation of the national health strategy and similar educational status of study population.

Maternal educational level showed significant statistical association with good awareness of obstetric danger signs during any of the three periods. Those mothers who were in high school $(\mathrm{AOR}=4.21,95 \% \mathrm{CI}:[1.10,16.15])$ and those who have diploma and above $(\mathrm{AOR}=10.20$, 95\%CI: [2.45, 42.41]) were 4.21 and 10.2 times more likely to have good awareness of obstetric danger signs as compared to those who were non educated. This is nearly comparable with findings from Burkina Faso, Ghana and Tanzania [26], rural Tanzania [5], and Debark town showed women having high school and above educational level were 5.80 times (AOR= 5.78, 95\%CI: [2.78 - 12.03]) more likely to have good awareness on danger signs of pregnancy than those who don't read and write [22]. This can be explained by educated women have better understanding of information transferred through different mass media and have greater ability to use such information in a desirable way. They have also better perceptions about benefit of on time obstetric care, birth preparedness and early seeking of skilled care providers. In addition, educated women have better decision-making capacity than their counterparts.

The other robust predictor of awareness of women on obstetric danger signs was husband educational level. Those women who have husband in high school (AOR $=5.50,95 \% \mathrm{CI}:[1.58$, 19.10]) and those who have diploma and above (AOR $=4.17$, 95\%CI: [1.17, 14.85]) educational level were 5.5 and 4.17 times more likely to have good awareness on obstetric danger signs than their counterparts. This is slightly less than study done in Mekelle city with (AOR: 8.92, 95\%CI; [1.1, 74.89]) [20]. Possible justification could be educated husband has better opportunity to health care service information thereby encourage his wife to decide on health care seeking behavior timely and can afford appropriate care and advice during pregnancy, labor, and postpartum.

Urban resident showed significant statistical association with good awareness of obstetric danger signs. Urban resident women were 5.7 times (AOR; 5.69, 95\% CI: [2.14, 15.08]) more likely to have awareness of obstetric danger signs than rural resident women. This was nearly similar with 
findings from aletawondo showed Being urban resident was strongly associated with mentioning at least two danger signs of pregnancy (OR=4.1; 95\%CI: [2.4, 7.0]) (27). This can be explained by the fact that urban resident women have better access to education, mass media, health care service and facilities due to short distance from their home, internet access, and easy transportation. In additional, the attitude of societies living in city favors timely health care seeking behavior than societies live in a village.

This study finding also showed that Mass media revealed statistically significant association with good awareness of obstetric danger signs. The likelihood of being improved awareness on obstetric danger signs was 3 times (AOR: 3.03, 95\% CI: [1.05, 8.75]) greater for mothers who were used sources of information for obstetric danger signs like Radio, TV program or reading from internet posts than their counter parts. This is nearly consistent with study done in Tsegedie with $(\mathrm{AOR}=2.41,95 \% \mathrm{CI}:[1.22,4.76])$ [21]. This can be justified by the fact that mass media is effective in information dissemination which improves awareness about health care information and available healthcare facilities. It also enhances between individual communications which could facilitate behavioral changes towards improvement of early health care seeking behavior.

There are some limitations to this study. Firstly, this study was done for those women who visit public health institutions of Adama city so the findings of this study may be difficult to generalize for women who did not visit health institutions. Secondly, causal relation between the different independent variables and women's awareness of obstetric danger signs cannot be inferred due to the nature of cross-sectional study.

\section{CONCLUSION}

This study showed that of all participants about $44.4 \%$ knew seven and above obstetric danger signs. This shows a significant proportion of mothers were unaware about the danger signs of pregnancy, labor and postpartum. This indicates that many mothers are more likely to delay in deciding to seek care due to low awareness of obstetric danger signs. The associated factors of awareness towards obstetric danger signs were maternal and Partner educational status, residence, and sources of information for obstetric danger signs.

Therefore, it needs to increase women's awareness on obstetric danger signs and associated factors through maternal and child health service by designing appropriate strategies including provision of information, education and communication targeting women, family, and the general community.

Women's husband-based health education on obstetric danger signs should be introduced in all health institutions and the community should be mobilized through mass media. Majority of the participants were urban resident, so further study needs to be conducted at rural area.

Acknowledgements: Special thanks go to the research assistants involved in data collection. We would like to thank also for all participants for their willingness and cooperation during the study. 


\section{References:}

1. World Health Organization. (2016). Maternal Health and Safe Motherhood Program. Mother-Baby Package: Implementing Safe Motherhood in Countries: practical guide. Geneva, Switzerland: WHO.

2. Federal Democratic Republic of Ethiopia, Ministry of Health. (2010). Management protocol on selected obstetrics topics, January, 2010.

3. Maternal and Neonatal Health Program. (2004). Monitoring birth preparedness and complication readiness: tools and Indicators for maternal and newborn health. Baltimore, USA.

4. Thaddeus, S., Maine, D. (1994). Too far to walk: Maternal mortality in context. Social Science and Medicine, 38(8), 1091-1110.

5. Pembe, A.B., Urassa, D.P., Carlstedt, A., Lindmark, G., Nystrom, L., Darj, E. (2009). Rural Tanzanian women's awareness of danger signs of obstetric complications. $B M C$ Pregnancy Childbirth. 9, 12.

6. WHO, UNICEF, UNFPA, World Bank Group and the United Nations Population Division. (2015). Trends in Maternal Mortality: 1990 to 2015: Estimates by WHO, UNICEF, UNFPA, World Bank Group and the United Nations Population Division. Geneva, Switzerland: WHO. 96 p.

7. Federal Democratic Republic of Ethiopia, Ministry of Health. Maternal Death Surveillance and Response (MDSR). (2014). Technical Guideline. Addis Ababa, Ethiopia: FMOH; 2014.

8. Central Statistical Agency (CSA). [Ethiopia], ICF International. Ethiopia Demographic and Health Survey 2016. (2017). Addis Ababa, Ethiopia, and Rockville, Maryland, USA: CSA and ICF International.

9. Federal Democratic Republic of Ethiopia, Ministry of Health. (2006). National Reproductive Health Strategy, 2006-2015. Addis Ababa, Ethiopia: FMOH.

10. Khan, K.S., Wojdyla, D., Say, L., Gülmezoglu, A.M., Van Look, P.F.A. (2006). WHO analysis of causes of maternal death: a systematic review 2006, 367(9616):1066-1074.

11. Smeele, P., Kalisa, R., van Elteren, M., van Roosmalen, J., van den Akker, T. (2018). Birth preparedness and complication readiness among pregnant women admitted in a rural hospital in Rwanda. BMC pregnancy and childbirth, 18(1), 190.

12. Assaf, S. (2018). Counseling and Knowledge of Danger Signs of Pregnancy Complications in Haiti, Malawi, and Senegal. Maternal and child health journal. 22(11),1659-67.

13. Markos, D., Bogale, D. (2014). Birth preparedness and complication readiness among women of child bearing age group in Goba woreda, Oromia region, Ethiopia. BMC Pregnancy and Childbirth, 14, 282.

14. Federal Democratic Republic of Ethiopia, National Plan Commission. (2017). The 2017 Voluntary National Reviews on SDGs of Ethiopia: Government Commitments, National Ownership and Performance Trends. Addis Ababa, Ethiopia: NPC; 2017. 
15. Starrs, A.M. (2006). Safe motherhood initiative: 20 years and counting. Lancet. 368(9542), 1130-1132.

16. Athayde, N., Maymon, E., Pacora, P., Romero, R. (2000). Premature or prelabour rupture of the fetal membrane. In: Ransom SB, Dombrowski MP, Moghissi KS, McNeeley SG, Munkarah AR, editors. Practical strategies in obstetrics and gynecology. Philadelphia: W.B. Saunders. p.349-365.

17. Klein, S. (1999). A book for midwives: a manual for traditional birth attendants and community midwives. Revised edition. London and Basingstoke: Macmillan Education.

18. WHO. (1996). Safe motherhood: care in normal birth: a practical guide. WHO/FRH/MSM/96.24. Geneva. 1996.

19. Solomon, A.A., Amanta, N.W., Chirkose, E.A., Badi, M.B. (2015). Knowledge About Danger Signs of Pregnancy and Associated Factors Among Pregnant Women in Debra Birhan Town, Central Ethiopia. Science Journal of Public Health, 3(2), 269-273.

20. Abiyot, T., Kassa, M., Buruh, G., Kidanu, K. (2015). Awareness of Obstetric Danger Signs and its Associated Factors among Pregnant Women in Public Health Institutions, Mekelle City, Tigray, Ethiopia 2014. Journal of Preganency \& Child Health,2(3) 1000167.

21. Hailu, D., Berhe, H. (2014). Knowledge about Obstetric Danger Signs and Associated Factors among Mothers in Tsegedie District, Tigray Region, Ethiopia 2013: Community Based Cross-Sectional Study. PLOS ONE 9(2), e83459.

22. Mengesha, E., Taye, H. (2014). The Level of Awareness on Danger Signs of Pregnancy and Associated Factors among ANC Attendant Pregnant Women in Debark Town, North West Ethiopia. Translational Medicine and Biotechnology, 2(5),1-12.

23. Bintabara, D., Mpembeni, R.N.M., Mohamed, A.A. (2017). Knowledge of obstetric danger signs among recently-delivered women in Chamwino district, Tanzania: a crosssectional study. BMC Pregnancy and Childbirth, 17, 276.

24. Kabakyenga, J.K., Östergren, P., Turyakira, E., Pettersson, K.O. (2011). Knowledge of obstetric danger signs and birth preparedness practices among women in rural Uganda. Reproductive Health, 8, 33.

25. Pembe, A. B., Carlstedt, A., Urassa, D.P., Lindmark, G., Nyström, L., Darj, E. (2010). Quality of antenatal care in rural Tanzania: counselling on pregnancy danger signs. $B M C$ Pregnancy and Childbirth, 10, 35.

26. Duysburgh, E., Ye, M., Williams, A. (2013). Counselling on and women's awareness of pregnancy danger signs in selected rural health facilities in Burkina Faso, Ghana and Tanzania. Tropical Medicine and International Health, 18(12), 498-1509.

27. Hailu, M., Gebremariam, A., Alemseged, F. (2010). Knowledge about obstetric danger signs among pregnant women in aletawondo district, Sidama zone, southern Ethiopia. Ethiopian Journal of Health Science, 20(1), 25-32.

28. Berhan, Y., Berhan, A. (2014). Review of maternal mortality in Ethiopia: a story of the past 30 years. Ethiop Journal of Health Science, 24 Suppl(0 Suppl), 3-14. 
29. Legesse, T., Abdulahi, M., Dirar, A. (2017). Trends and causes of maternal mortality in Jimma University specialized Hospital, southwest Ethiopia: a matched case-control study. International Journal of Women's Health, 9, 307-313.

30. Amenu, G., Mulaw, Z., Seyoum, T., Bayu, H. (2016). Knowledge about Danger Signs of Obstetric Complications and Associated Factors among Postnatal Mothers of Mechekel District Health Centers, East Gojjam Zone, Northwest Ethiopia. Scientifica, 1-7. 